\title{
Formándonos para transformarnos, transformándonos para incidir
}

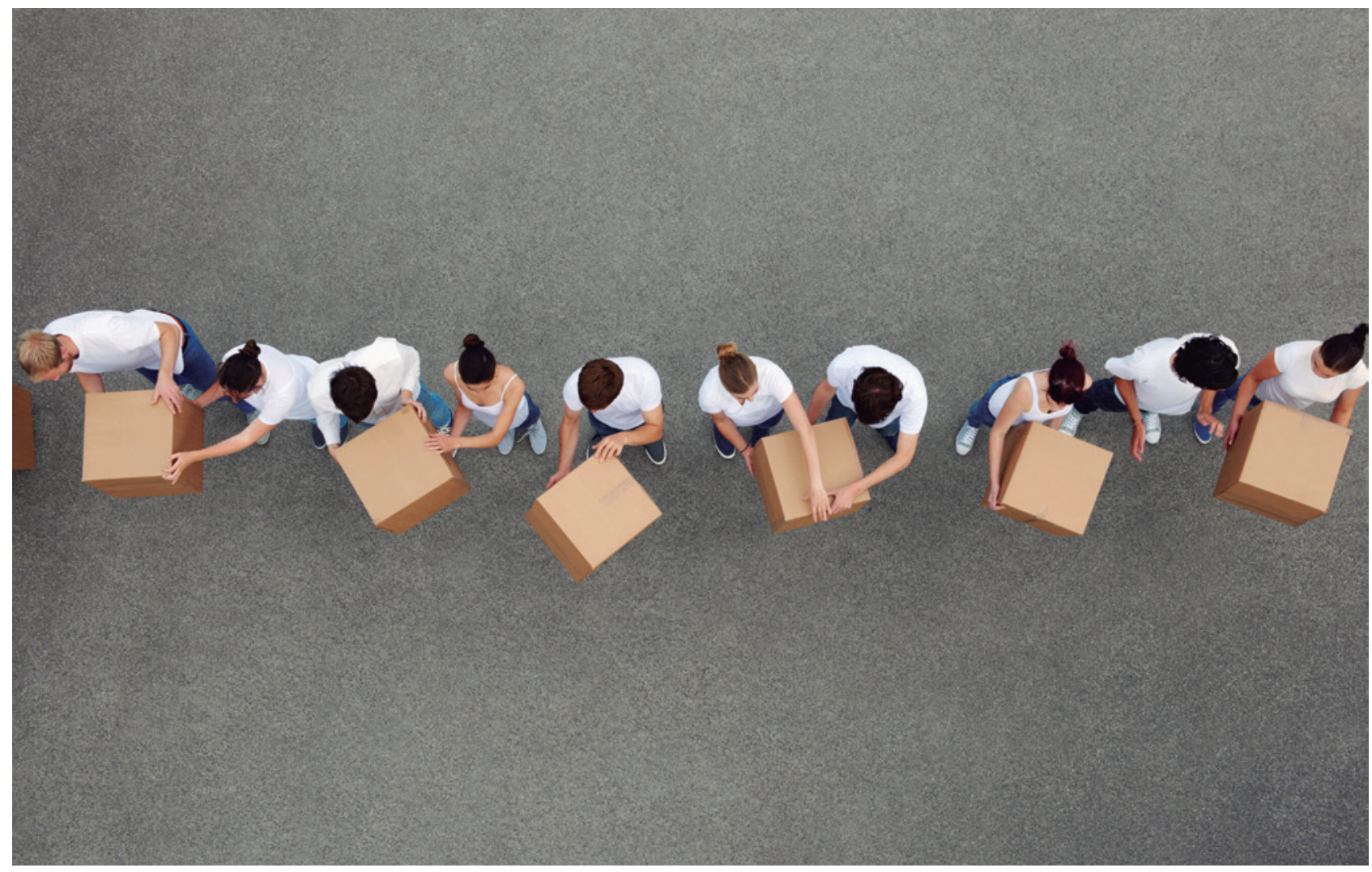

Fe y Alegría durante los últimos años ha desarrollado procesos formativos con las juventudes, con ellos y ellas ha ido desarrollando un camino de formación para

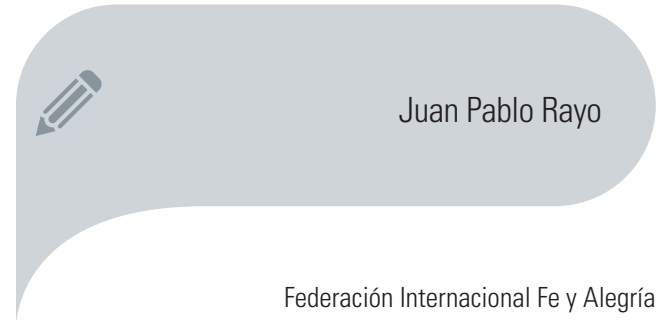
fi.jovenes-ciudadania@feyalegria.org la incidencia. Algunos de los principales aprendizajes han sido poder reconfigurar las maneras de participar en las comunidades, construir trabajo en red y pensar procesos formativos desde el desarrollo de capacidades con una perspectiva de la ciudadanía global. 
En Latinoamérica existen diversas organizaciones sociales y educativas que han dedicado sus esfuerzos al trabajo por las juventudes, para el caso de este artículo se hará referencia a la experiencia de Fe y Alegría Colombia (Movimiento de Educación Popular y de Promoción Social).

Tras una trayectoria de más de 10 años, se han logrado evidenciar aspectos clave en términos de intencionalidad formativa y de acompañamiento a las juventudes. Para comprender estos aprendizajes será necesario hacer un recorrido en el tiempo.

Comenzando con los primeros pasos (2007-2010), encontramos que estos procesos iniciales estaban enmarcados hacia la formación de valores humanocristianos. El objetivo era potenciar los proyectos personales de los jóvenes y a su vez ayudarles a comprender la importancia de tener propósitos en la vida. En esta etapa era clave reconocer que las juventudes logran estar comprometidas con los procesos donde son tenidas en cuenta y en donde se las escuchaba. Estos dos últimos aspectos marcaron pistas claves sobre la permanencia de las juventudes en los procesos formativos y reafirmaba la necesidad que manifestaban por ser y sentirse parte de "algo" y a su vez de ir encontrando sentido a lo que se es y se puede llegar a ser y hacer. Aun así y pese a estos avances, se identificaba que estos jóvenes eran individualmente muy buenos, pero les costaba muchísimo encontrarse con otros para ponerse de acuerdo y trabajar colaborativamente a favor de sus comunidades. Asimismo, se evidenciaba que mientras estuviesen presentes las educadoras o facilitadores de estos grupos, estos se mantenían unidos y fortalecidos, pero cuando estas personas no estaban o por alguna razón debían dejar el acompañamiento de la experiencia, estos grupos de jóvenes dejaban de reunirse y en la mayoría de los casos se disolvían. Además, es importante mencionar que estos grupos se daban en el contexto escolar y muy pocos de ellos estaban inmersos en los barrios y comunidades.

Sumado a lo anterior, todo este movimiento se produce en un panorama

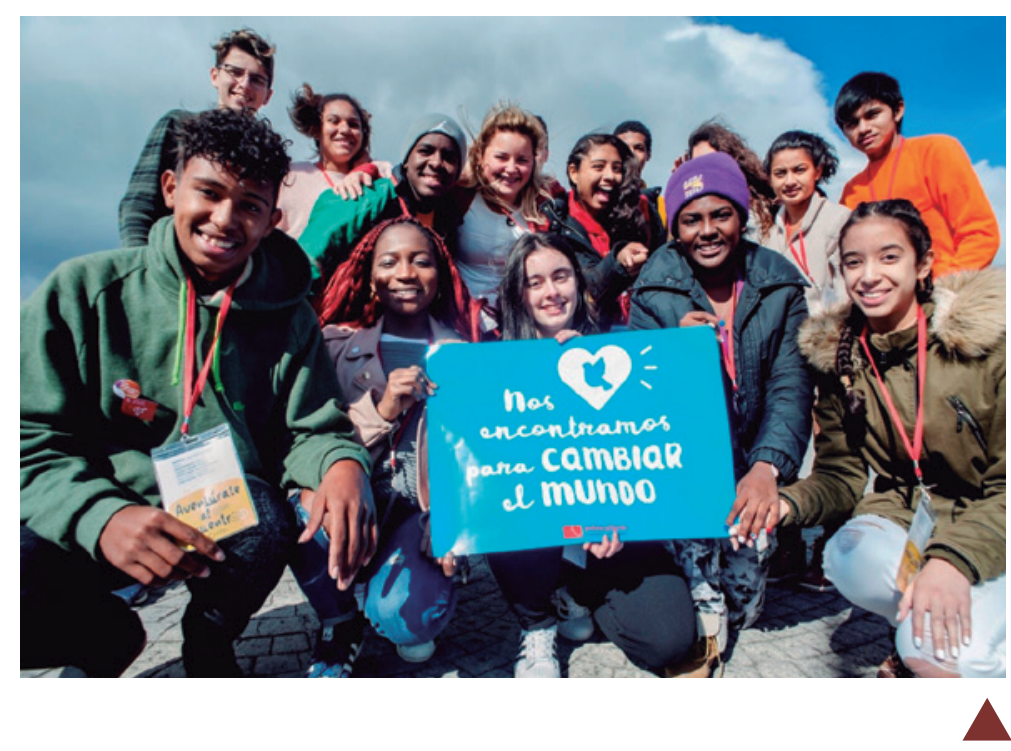

colombiano donde confluyen diversas situaciones que cuestionan y confrontan los procesos de acompañamiento a las juventudes. Tomando como referencia el diagnóstico realizado por el equipo de desarrollo comunitario de Fe y Alegría Colombia (2010-2011), se evidenciaba lo siguiente:

$\boldsymbol{\lambda}$ Las situaciones de inequidad e injusticia se manifestaban en todo el territorio colombiano.

$\boldsymbol{\lambda}$ Los altos índices de violencia estaban presentes en sus diversas manifestaciones, pero especialmente centrados en: las mujeres cabeza de hogar, los niños y niñas, la vinculación de jóvenes a grupos de pandillas y violentados para realizar actividades al margen de la ley.

$\boldsymbol{\lambda}$ Las oportunidades laborales se encontraban situadas en ámbito de lo informal. En el campo del trabajo formal el abuso laboral estaba representado en los salarios injustos, largas jornadas laborales y abuso de poder por parte de los empleadores. Según la OIT, el desempleo juvenil en Colombia aumentaba considerablemente y a su vez la tasa de informalidad.

त El conflicto armado, como uno de los conflictos más antiguos de América, se iba recrudeciendo por el aumento y complejidad de los actores armados (grupos guerrilleros y paramilitares, las fuerzas armadas estatales y la policía nacional, narcotráfico, pandillas urbanas...) que cometían actos de violencia y abusos contra los civiles y que, habitualmente, quedaban en la impunidad.

入 Por otro lado, aumentaba el número de procesos de desplazamiento forzado, 


\section{IIII. ÁQORA DE DROFESORES}

入 Del liderazgo individual a liderazgos colaborativos y distribuidos: reconociendo la importancia de seguir potenciando a las juventudes desde su individualidad, pero con la firme intención de que puedan tomar conciencia de que en la medida que se encuentren y articulen con otros podrán Ilegar aún más lejos que si van solos o pensando de manera individual o particular. En palabras de Harris y Chapman (2002) "el liderazgo distribuido aprovecha las habilidades de los otros en una causa común, de tal forma que el liderazgo se manifiesta a todos los niveles". En este sentido las juventudes se han ido sintiendo, cada vez más, parte de sus comunidades y han reconocido que sus capacidades sumadas con las de los otros compañeros, pueden ser mucho más potentes al momento de generar procesos de transformación.

入 Resignificación y fortalecimiento de la participación donde esta pueda ser comprendida más allá de un deber y un derecho ciudadano; donde se pueda asumir de manera más comprometida, en palabras de Velázquez (1986):

[...] como un proceso social que resulta de la acción intencionada de individuos y grupos en busca de metas específicas, en función de intereses diversos y en el contexto de tramas concretas de relaciones sociales y de poder. Es, en suma, un proceso en el que distintas fuerzas sociales, en función de sus respectivos intereses (de clase, de género, de generación), intervienen directamente 0 por medio de sus representantes en la marcha de la vida colectiva con el fin de mantener, reformar o transformar los sistemas vigentes de organización social y política.

入 Reflexiones alrededor del poder que tiene la juventud para aportar sus pensares y propuestas de cambio. Otro de los grandes aprendizajes es que este ha sido un proceso en el que las juventudes han ido reconociéndose como actores de transformación, en la medida que han ido reconociendo sus capacidades, las capacidades de los que les rodean y el sin número de posibilidades que tienen y que pueden llegar a generar para
Un ciudadano o ciudadana en la actualidad, para comprender el mundo en el que vive, integrarse en él de manera satisfactoria y tener la capacidad de influir y transformar su entorno, necesita ser capaz de desarrollar una serie de competencias asociadas a la interculturalidad, la igualdad de género y la participación.

Una ciudadanía partícipe y comprometida con el bien común tiene mayores posibilidades de influencia y de transformación social. Aquí se presentan conocimientos, habilidades y actitudes que los docentes pueden utilizar para orientar la práctica educativa:

\begin{tabular}{|c|c|c|}
\hline \multicolumn{3}{|c|}{ Participación } \\
\hline Conocimientos & Habilidades & Actitudes \\
\hline $\begin{array}{l}\text { Comprender el sentido de } \\
\text { la participación social } \\
\text { Códigos de conducta y } \\
\text { maneras de comportarse } \\
\text { Conceptos básicos de tipo } \\
\text { político e institucional } \\
\text { Democracia } \\
\text { Derechos civiles } \\
\text { Dignidad humana } \\
\text { Derechos Humanos } \\
\text { Funcionamiento de las } \\
\text { principales instituciones } \\
\text { del país, región, ciudad } \\
\text { Componentes de la } \\
\text { identidad nacional, } \\
\text { regional y local } \\
\text { Dimensión multicultural } \\
\text { del propio contexto, del } \\
\text { país, de Europa y del } \\
\text { mundo } \\
\text { Concepto de bien común } \\
\text { Concepto de } \\
\text { interdependencia } \\
\text { Concepto de igualdad }\end{array}$ & $\begin{array}{l}\text { Comunicación constructiva } \\
\text { Expresar y comprender } \\
\text { diferentes puntos de vista, } \\
\text { incluido el propio } \\
\text { Diálogo y argumentación } \\
\text { Cooperación } \\
\text { Resolución de conflictos } \\
\text { Negociar y consensuar } \\
\text { Participación en la vida } \\
\text { social y política } \\
\text { Enfrentarse y superar el } \\
\text { estrés, la frustración y la } \\
\text { rabia y canalizarlas de } \\
\text { forma constructiva } \\
\text { Trabajo en equipo } \\
\text { Capacidad crítica } \\
\text { Conocimiento y manejo } \\
\text { de las propias emociones, } \\
\text { necesidades y límites } \\
\text { Tratar con gente de } \\
\text { diferentes culturas } \\
\text { Creatividad, capacidad de } \\
\text { crear nuevas opciones } \\
\text { Pensamiento alternativo } \\
\text { Proactividad }\end{array}$ & $\begin{array}{l}\text { Respeto a las demás } \\
\text { personas } \\
\text { Apertura al encuentro } \\
\text { Superación de } \\
\text { prejuicios y estereotipos } \\
\text { Disposición al } \\
\text { compromiso } \\
\text { Solidaridad } \\
\text { Asertividad } \\
\text { Empatía } \\
\text { Integridad } \\
\text { Disposición a tomar } \\
\text { parte en las actividades } \\
\text { de la comunidad y en las } \\
\text { decisiones políticas } \\
\text { Interculturalidad } \\
\text { Aprecio de la diversidad } \\
\text { Responsabilidad } \\
\text { Corresponsabilidad } \\
\text { Compasión } \\
\text { Sentimiento de } \\
\text { pertenencia a una } \\
\text { comunidad humana }\end{array}$ \\
\hline
\end{tabular}

el cambio que ellos quieren. Desde la perspectiva del empoderamiento juvenil ha sido profundamente esperanzador ver como las juventudes "Ya no se quedan quietos, ni callados", es y seguirá siendo un reto y un compromiso junto con ellos pensar como el "poder" que se tiene se puede desarrollar y reconfigurar de tal manera que les permita seguir trabajando en pro de sus comunidades. En palabras de Torres (2009):

El empoderamiento juvenil se refiere a la participación en la adopción de decisiones. Empoderar a los jóvenes 


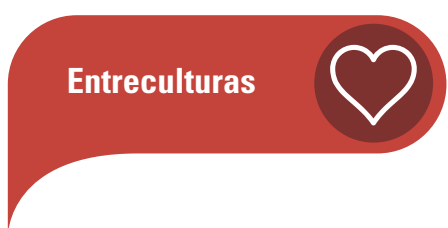

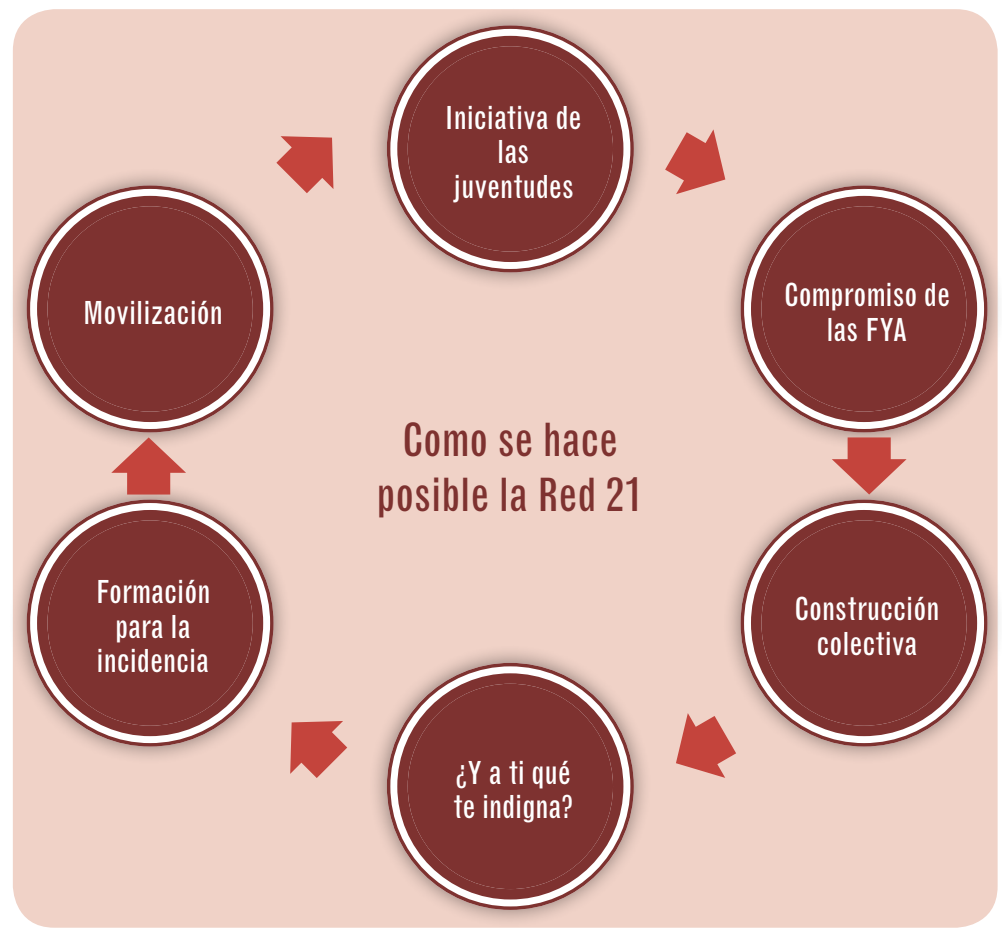

significa darles la oportunidad de tomar decisiones sobre asuntos que tienen impacto en sus vidas. ¡Los jóvenes no son pasivos, son agentes activos para el desarrollo y el cambio!

Pero más allá de "darles la oportunidad" es reconsiderar que ellos pueden ser gestores de sus propios desarrollos y que sus propuestas pueden hacer de este mundo un lugar mucho mejor donde todos podamos convivir.

7 EnReDandonos: en este mismo proceso de reflexiones y de construcción colectiva, las juventudes fueron dándose cuenta de que juntos y organizados podían lograr mayor impacto no solo en sus comunidades, sino en todo el territorio nacional. Fue así como en agosto de 2015, en el marco del primer encuentro nacional de jóvenes por la Paz, organizado por la propuesta de ParticipAcción Juvenil, las juventudes se dieron la oportunidad de reflexionar sobre aquellas situaciones que les indignaban, aquellas cosas que no podían seguir aceptado sobre su realidad y que a su vez estuviesen dispuestos a transformar. En ese pensar fueron considerando la necesidad de organizarse como una red de jóvenes a la que denominaron "Red Juvenil de Fe y Alegría Colombia" y paralelo a ello acordaron que cada 29 de agosto iban a movilizarse sobre aquellas situaciones que querían transformar de sus comunidades. Es así como estas juventudes, año tras año, han ido pensándose colectivamente un plan de trabajo formativo y de incidencia donde van marcando el horizonte compartido.

入 El aquí y ahora. Paralelo a este ejercicio de organización de las juventudes a nivel Fe y Alegría Colombia, se produce la celebración de los 60 años de la Federación Internacional de Fe y Alegría y para ello se decide hacer un congreso internacional denominado "Culturas juveniles, ciudadanías y Paz". En este espacio, las juventudes tuvieron la oportunidad de reflexionar sobre sus principales situaciones de indignación, las diversas manifestaciones de violencia y la manera en la que podían aportar a la transformación de dichas situaciones desde una perspectiva de cultura de paz. Asimismo, fue la oportunidad para que se pensaran como una gran red de hombres y mujeres jóvenes de más de 21 lugares geográficos del mundo (América, Europa y África), en dicho espacio las juventudes reafirmaron su compromiso:

\footnotetext{
Para ello, nos comprometemos a ser parte de una ciudadanía juvenil para la paz con perspectiva de género que logre impulsar y visibilizar nuestra acción comprometida en la construcción de otro mundo posible y necesario. Para lograrlo, seguiremos formándonos para transformarnos y transformarnos para incidir.
}

Esta afirmación de las juventudes ha sido una clave orientadora tanto para ellos en sus procesos formativos y de acción, como para quienes los acompañan. Y esto nos deja un nuevo aprendizaje y es que, si realmente se quiere aportar para transformar este mundo, se debe iniciar por experiencias formativas que apunten a la transformación de los que participan de ellos y que a su vez estos, transformándose, puedan pensar en cómo pueden incidir en sus realidades. Es así como esta red de jóvenes ha ido tomando forma poco a poco. No había pasado un año cuando en octubre de 2016, después 
de numerosos diálogos entres maestros y jóvenes, se celebra en Lima (Perú) el Congreso Internacional de Fe y Alegría "Educación, Cultura de paz, Ciudadanía y Jóvenes" en el que las juventudes lograron darle nombre a la red de jóvenes que ya habían iniciado, la denominaron Red Generación 21. Seguido a este momento, se propusieron continuar reflexionando alrededor de varios temas como la cultura de paz, la equidad de género, la educación popular de calidad y la ciudadanía global para la incidencia. Esta propuesta de la Red Generación 21 ha sido incluida en el plan de prioridades de la Federación Internacional de Fe y Alegría (2016-2020), donde las juventudes han logrado que este movimiento de educación reconfigure la mirada del trabajo, y pasar de verlos como beneficiarios a compañeros de transformación, en actores políticos de transformación. Para ello ha sido fundamental escucharlos, permitirles ser quienes son, reconociendo su creatividad y compromiso con los procesos de los que son parte, se sienten parte y han tomado parte.

Teniendo presente lo anterior, es importante señalar que estas dos redes son claro ejemplo de cómo acompañar a las juventudes puede resultar todo un reto a largo plazo. Sin embargo, este es un reto que vale la pena vivir. Por eso, en la medida en la que quienes acompañen procesos juveniles comprendan que la ciudadanía global es justamente ir construyendo ciudadanía desde y con las personas, desde sus propias realidades, pero a su vez encontrando relación con las otras situaciones que pasen en otros

\section{HEMOS HABLADO DE}

\section{Juventudes; participación; ciudadanía; educación; incidencia.}

Este artículo fue solicitado por PADRES Y MAESTROS en diciembre de 2017, revisado y aceptado en marzo de 2018.

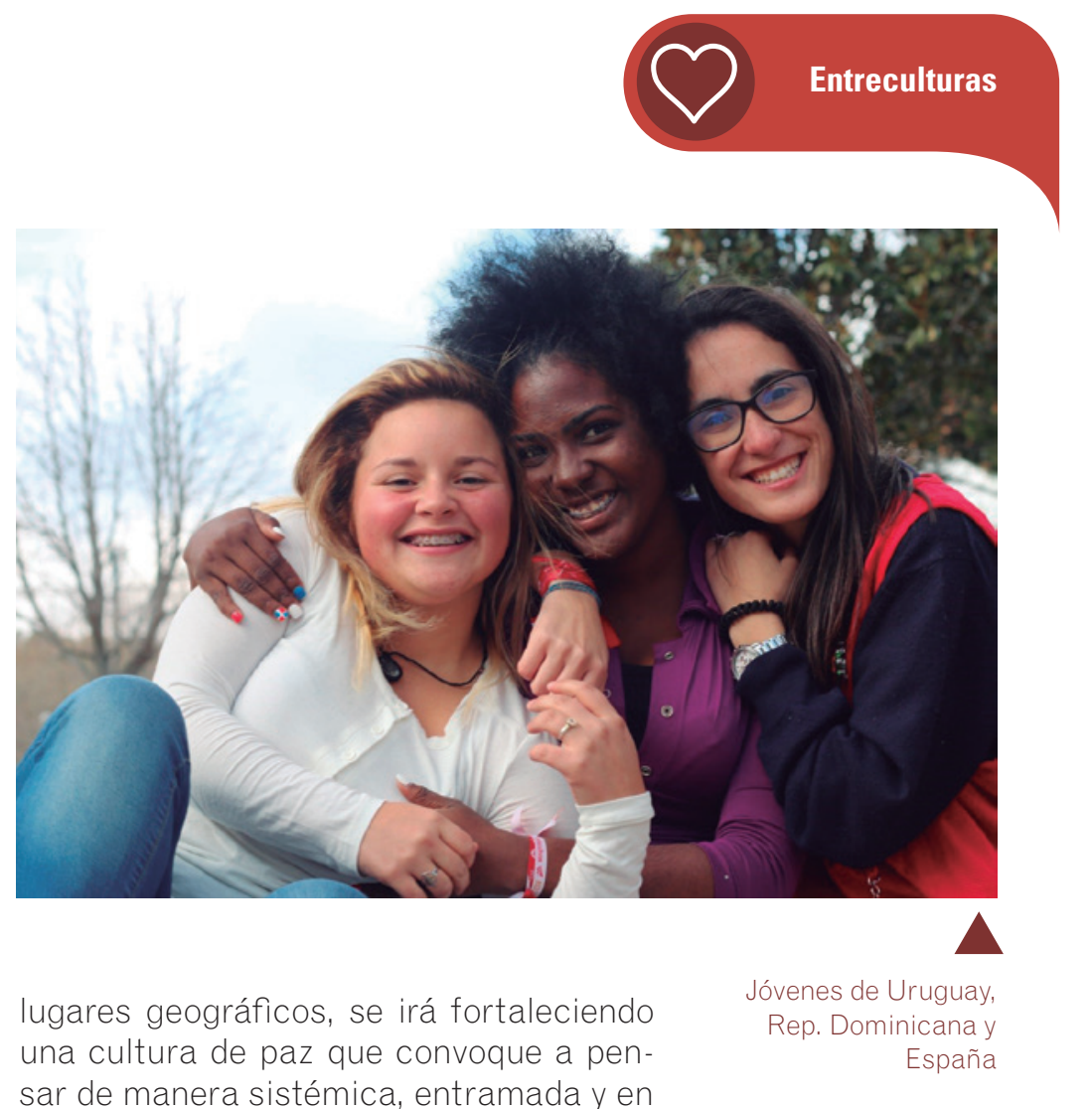

constante relación. Lo anterior según Capra (1996) "exige cambiar de manera radical nuestra percepción sobre la vida, de nuestro pensamiento y en tercer lugar de nuestros valores, comprendiendo estos desde la perspectiva de las relaciones".

Todo este camino construido es un camino que aún se sigue tejiendo, que se ha ido reconfigurando de acuerdo a lo vivido y pensado junto a las juventudes. En este momento es preciso reconocer que esta experiencia compartida genera muchas más inquietudes que respuestas, pues el mismo ritmo de este mundo y la manera en la que va cambiando, exige nuevas maneras de abordar, de comprender y construir con otros, y es precisamente esto lo que seguirá marcando el camino a seguir. Por eso, hoy más que qué temas o contenidos formativos, será necesario pensar en ¿qué capacidades se necesitan desarrollar en las juventudes y todas las demás personas para que puedan ser transformadores de esta realidad incierta, volátil y ambigua? Pero además ¿qué condiciones deben generarse para que todo aquello que se propongan suceda, tal y como lo sintieron y pensaron?•

\section{DARR SABER MÁS}

Fe y Alegría Colombia. http://www.feyalegria. org.co/ 